\title{
Deformation and Fracture of High-Temperature Steels at Different Temperatures and Loading Rates
}

\author{
E. A. Kondryakov, S. V. Lenzion, and V. V. Kharchenko \\ Pisarenko Institute of Problems of Strength, National Academy of Sciences, Kiev, \\ Ukraine
}

Charpy impact tests were conducted at different temperatures and loading rates. Temperature dependences of the crack initiation and propagation energies were determined for carbon steel 45 steels St. 3 and 15Kh2NMFA from the load-time curves obtained with due account of the impact test results. The effect of the loading rate on the temperature dependence of the impact toughness was analyzed within the range from 1 to $4.4 \mathrm{~m} / \mathrm{s}$.

Keywords: high-temperature steels, Charpy specimen, instrumented impact testing machine, impact toughness, crack initiation and propagation energy, brittle-toductile transition temperature, crack propagation rate.

Introduction. Brittle-to-ductile transition temperature (BDTT) is one of the major material characteristics when it comes to assessing strength and reliability of structures and constructions. It is determined using various test methods. Charpy impact testing is one of the simplest and most widespread approaches. In the course of such tests, the BDTT is evaluated by processing the dependences of the impact toughness on the test temperature [1-3]. Here, the fact that the impact toughness is an integral energy characteristic, which includes the specimen strain energy and the crack initiation and propagation energies, should be taken into account.

In order to get more information about the material behavior, instrumented impact testing machines are used nowadays, which ensure recording of the force vs time curves during testing [1,4-7]. The application of modern high-speed data acquisition systems extends appreciably the possibilities of processing the information obtained from the impact tests. This information allows analyzing different approaches to the determination of the BDTT and the energy spent at different stages of deformation and fracture of Charpy specimens in the course of impact tests [2].

The objective of this work is to study the behavior of high-temperature steel 15Kh2NMFA versus St. 3 and 45 steels at different temperatures and loading rates using an instrumented vertical impact testing machine.

Experimental Technique and Processing of Results. Impact tests were carried out using an instrumented vertical impact testing machine equipped with a multichannel system for high-speed recording of forces and strains and a system for specimen cooling and heating in the temperature range from -150 to $400^{\circ} \mathrm{C}$ [8]. Standard Charpy specimens of size $55 \times 10 \times 10 \mathrm{~mm}$ of St. 3, 45, and $15 \mathrm{Kh} 2 \mathrm{NMFA}$ steels were the objects of the study $[9,10]$. The impact velocity $V_{0}$ varied from 1.0 to $5 \mathrm{~m} / \mathrm{s}$ and the temperature from -135 to $315^{\circ} \mathrm{C}$. 
From the force vs time curves, $P(t)$, obtained with a sufficiently high resolution in both coordinates (Fig. 1), it is possible to determine the energy spent on the specimen fracture and to divide it into components, namely the energy prior to the instant of crack formation (initiation) and the energy of the ductile and/or brittle crack propagation [5]. Methods for determining the values of the above energy components are described elsewhere [11].

Analysis of Test Results. Typical force vs time curves are presented in Fig 1.

A zone of ductile crack extension can be clearly seen on the test diagrams plotted for the specimens of steel 15Kh2NMFA at the test temperature above $35^{\circ} \mathrm{C}$.

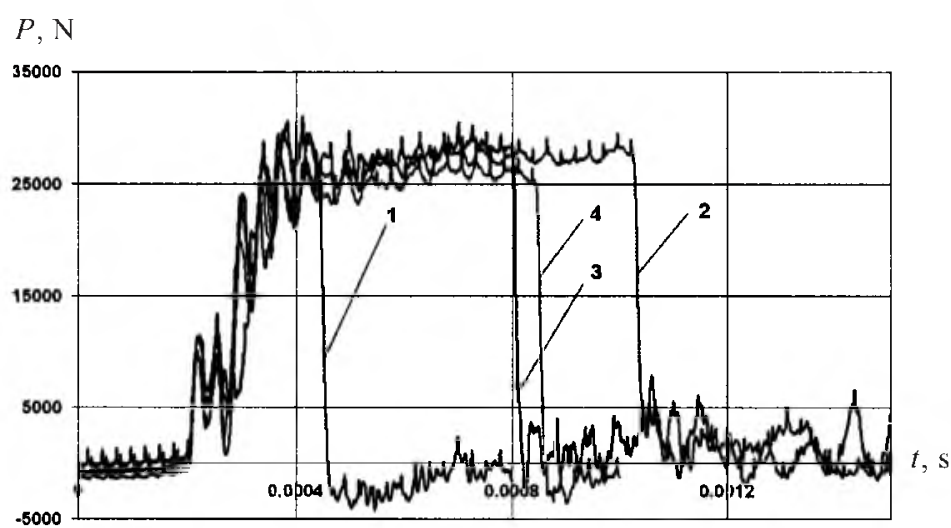

a

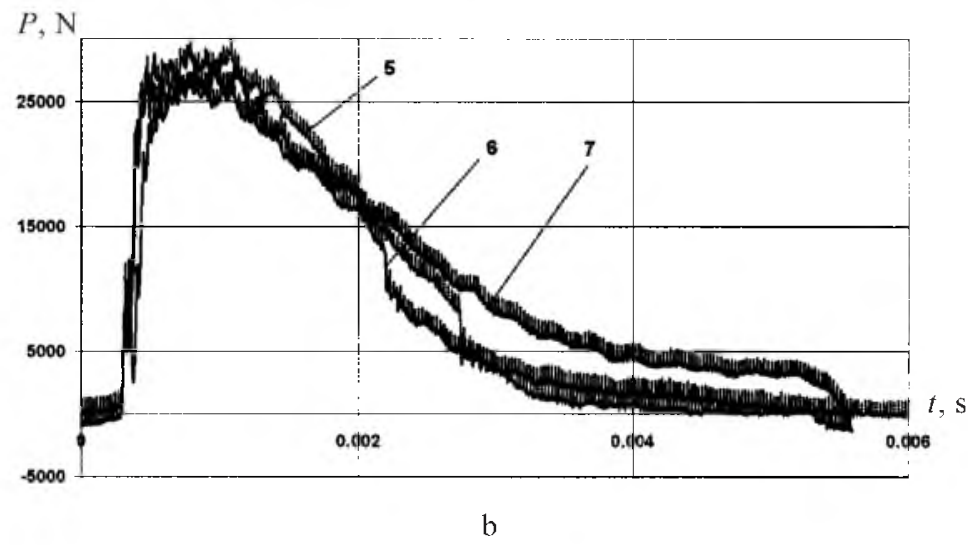

Fig. 1. $P(t)$ curves for steel $15 \mathrm{Kh} 2 \mathrm{NMF} \Lambda$ at loading rates of $4.4(\mathrm{a})$ and $5 \mathrm{~m} / \mathrm{s}$ (b) at different test temperatures: (I) $T=-20^{\circ} \mathrm{C}$, (2) $T=-10^{\circ} \mathrm{C}$, (3) $T=0^{\circ} \mathrm{C}$, (4) $T=10^{\circ} \mathrm{C}$, (5) $T=35^{\circ} \mathrm{C}$, (6) $T=$ $50^{\circ} \mathrm{C},(7) \mathrm{T}=100^{\circ} \mathrm{C}$.

In order to estimate the mean crack propagation rate in a specimen, it is necessary to determine the crack propagation time and the change in its length. The crack propagation time can be determined from the force vs time, $P(t)$, curves. High sensitivity of the digital signal recording system allows increasing the scale of the signal in time within the region of the brittle crack propagation [11]. The obtained estimates show that the duration of the brittle jump is $t=15-30 \mu \mathrm{s}$. The change in the crack length can be determined from the zones of 
brittle and ductile fracture on the specimen fracture surfaces. The occurrence of various fracture patterns is observed at different test temperatures. The obtained values of the fracture time and the crack length can be used to estimate the crack propagation rate.

The ductile crack propagation rate varies from 1 to $20 \mathrm{~m} / \mathrm{s}$ for all the investigated steels. The propagation rate of a brittle crack, $V_{b}$, is much higher than that of a ductile crack. As seen from Fig. 2, the brittle crack propagation rate in the brittle-to-ductile transition zone (DBTZ) decreases significantly with increasing test temperature. For steel 3 and steel 45, $V_{b}$ varies in the range from 150 to $400 \mathrm{~m} / \mathrm{s}$. At low test temperatures (below those of the DBTZ), $V_{b}$ varies in the range from 300 to $400 \mathrm{~m} / \mathrm{s}$, while within the DBTZ it varies in the range from 150 to $350 \mathrm{~m} / \mathrm{s}$. A similar behavior is observed for steel St. 3. For steel $15 \mathrm{Kh} 2 \mathrm{NMFA}, V_{b}$ varies in the range from 50 to $600 \mathrm{~m} / \mathrm{s}$ (Fig. 2). At test temperatures below those of the DBTZ, $V_{b}$ varies in the range of $300-600 \mathrm{~m} / \mathrm{s}$, while within the DBTZ it varies in the range of $100-400 \mathrm{~m} / \mathrm{s}$.

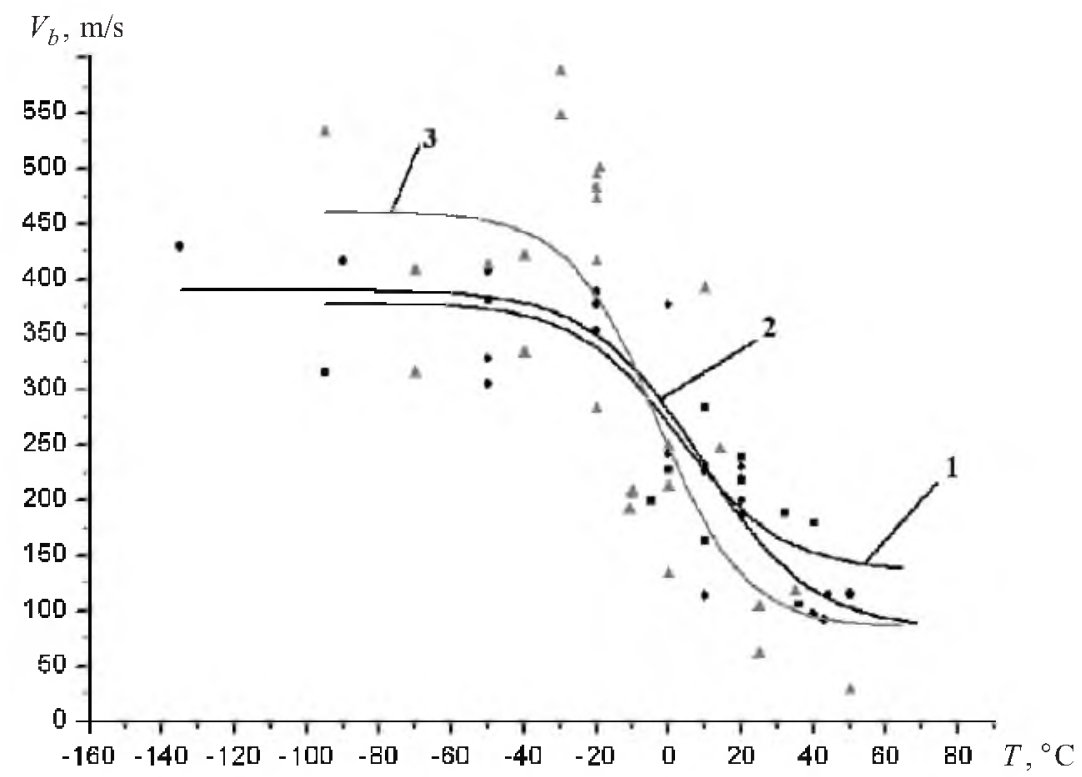

Fig. 2. Temperature dependence of the brittle crack propagation rate for a Charpy specimen of different steels: (1) St. 3, (2) 45, (3) 15Kh2NMFA. (Curves $1-3$ are approximations of the experimental data.)

Figures 3 and 4 show how the components of the strain and fracture energy of Charpy specimens made of 15Kh2NMFA and 45 steels depend on the test temperature at the loading rate $V_{0}=4.4 \mathrm{~m} / \mathrm{s}$. The behavior of the total strain and fracture energy, including its components, is similar for all the steels studied. It can be seen from the given curves that the major part of the energy is spent on the ductile fracture, whereas the energy spent on brittle fracture is insignificant (about $2 \mathrm{~J}$ ) and it practically does not change with temperature, the DBTZ included. On the upper shelf, the ductile fracture energy is about $60-70 \%$ (for steel 15Kh2NMFA it is about $150 \mathrm{~J}$ ) of the total fracture energy, whereas on the lower shelf, the crack initiation energy makes a decisive contribution to the total fracture energy. 


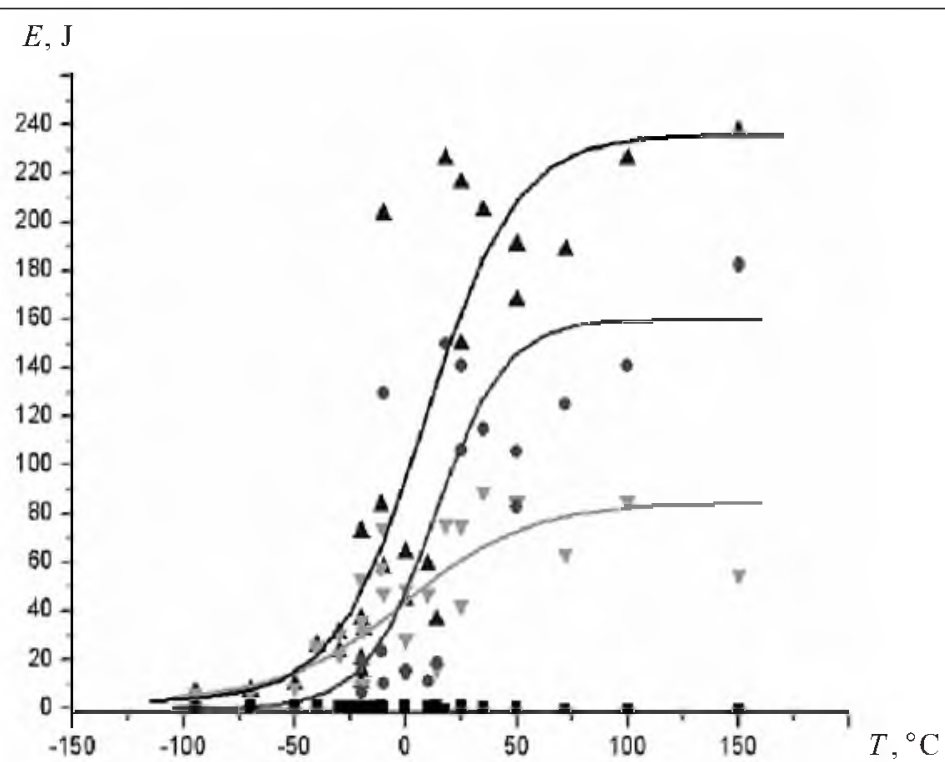

Fig. 3. Temperature dependence of the total strain and fracture energy $E_{t}(\mathbf{A})$ and its components: crack initiation energy $E_{i}(\boldsymbol{\nabla})$, ductile fracture energy $E_{d}(\bullet)$, and brittle fracture energy $E_{b}(\boldsymbol{\square})$ for steel $15 \mathrm{Kh} 2 \mathrm{NMFA}$.

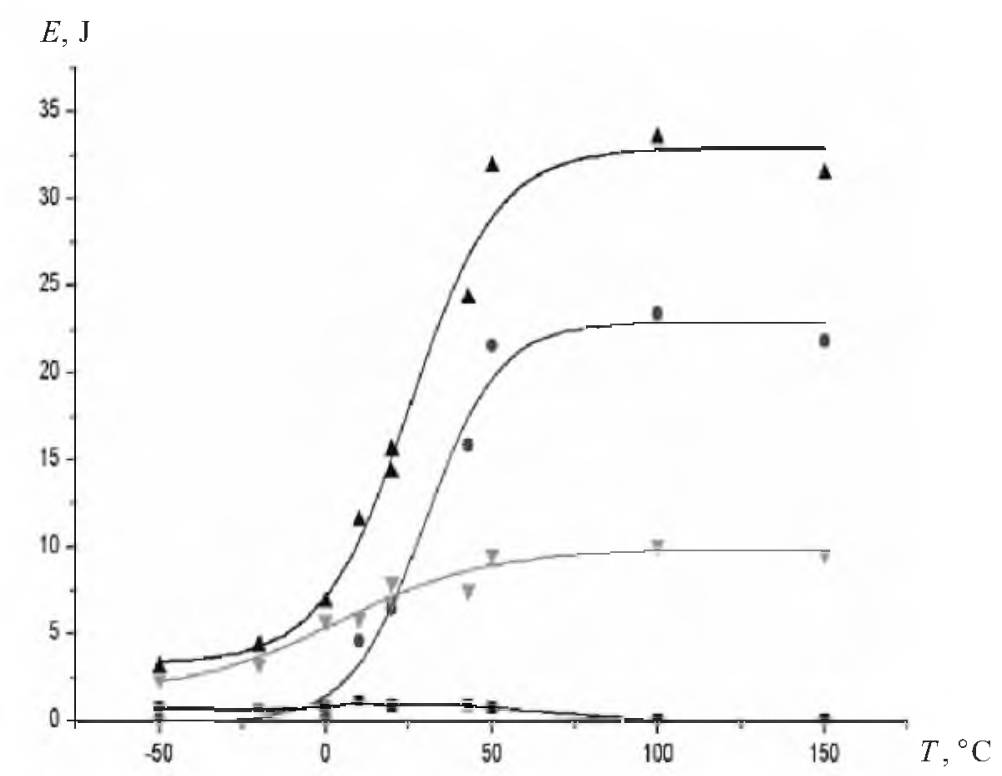

Fig. 4. Temperature dependence of the total strain and fracture energy $E_{t}(\boldsymbol{\Delta})$ and its components: crack initiation energy $E_{i}(\boldsymbol{\nabla})$, ductile fracture energy $E_{d}(\bullet)$, and brittle fracture energy $E_{b}(\boldsymbol{\square})$ for steel 45 .

Within the upper shelf region, the crack initiation energy remains practically unchanged with a rise in the impact velocity, while the ductile crack propagation energy increases considerably (by 50\%) with a rise in the loading rate from $2 \mathrm{~m} / \mathrm{s}$ to $4 \mathrm{~m} / \mathrm{s}$. 
The behavior of the crack initiation energy is similar to that of the total fracture energy, but the BDTT determined from the temperature dependence of the crack initiation energy (by analogy with static tests) is considerably higher than that evaluated from the temperature dependence of the total fracture energy. For steel $15 \mathrm{Kh} 2 \mathrm{NMFA}$, this difference equals to $20-30^{\circ} \mathrm{C}$ depending on the energy level at which the BDTT is determined.

Conclusions. The Charpy impact tests performed using an instrumented vertical impact testing machine made it possible to obtain the temperature dependences of the crack initiation and propagation energies for a heat-resistant steel 15Kh2NMFA as compared to carbon steel 45 and steel St. 3 at the loading rates within the range from 1 to $5 \mathrm{~m} / \mathrm{s}$.

The values of the brittle fracture energy do not exceed $2 \mathrm{~J}$, whereas those of the ductile fracture energy reach $150 \mathrm{~J}$.

It has been shown that at ductile fracture, the crack propagation rate in Charpy specimens made of heat-resistant steel $15 \mathrm{Kh} 2 \mathrm{NMFA}$ is from 1 to $20 \mathrm{~m} / \mathrm{s}$, whereas at brittle fracture, it is from 50 to $600 \mathrm{~m} / \mathrm{s}$. For steels 45 and St. 3, the value of $V_{b}$ varies within the range from 150 to $400 \mathrm{~m} / \mathrm{s}$. The rate of the brittle crack propagation decreases considerably with an increase in the test temperature.

1. N. A. Makhutov, E. M. Morozov, and Yu. G. Matvienko, "History and development of impact tests in Russia," in: Proc. Charpy Centenary Conf (Oct. 2-5, Poitiers), France (2001), pp. 557-566.

2. Proc. Charpy Centenary Conf (Oct. 2-5, Poitiers), Vol. 1-2, France (2001).

3. A. Ya. Krasovskii, Yu. A. Kashtalyan, and V. N. Krasiko, Investigation into the Crack Growth Resistance of Pressure Vessel Steels under Static and Dynamic Loading with Allowance for the Size-Scale Effect of Tested Specimens [in Russian], Preprint, National Academy of Sciences of Ukraine, Institute of Problems of Strength, Kiev (1982).

4. B. Tanguy, J. Besson, R. Piques, and A. Pineau, "Ductile-to-brittle transition of an A508 steel characterized by Charpy impact test. Pt. I: Experimental results," Int. J. Fract., 72, 49-72 (2005).

5. C. Gallo, J. A. Alvarez, F. Gutierrez-Solana, and J. A. Polanco, "Predicting crack arrest behavior of structural steels using small-scale material characterization tests," in: Proc. Charpy Centenary Conf (Oct. 2-5, Poitiers), France (2001), pp. 661-668.

6. O. Ya. Znachkovskii and I. V. Novikov, "Recording strain diagrams in low-temperature impact bending tests," Strength Mater., 4, No. 12, 14721474 (1972).

7. V. A. Strizhalo, O. Ya. Znachkovskii, and L. S. Novogrudskii, "Propagation of cracks in structural alloys at a temperature of 4.2 K," Strength Mater., 29, No. 6, 586-589 (1997).

8. E. A. Kondryakov, V. N. Zhmaka, V. V. Kharchenko, et al., "System of strain and load measurement in dynamic testing of materials," Strength Mater., 37, No. 3, 331-335 (2005). 
9. ISO 14556. Steel. Charpy V-Notch Pendulum Impact Test. Instrumented Test Method, Introduced 05.01.2005.

10. GOST 9454-78. Metals. Method for Carrying Out Impact Bending Tests at Low, Room, and Elevated Temperatures [in Russian], Introduced January 1, 1979.

11. V. V. Kharchenko, E. A. Kondriakov, V. N. Zhmaka, et al., "The effect of temperature and loading rate on the crack initiation and propagation energy in carbon steel charpy specimens," Strength Mater., 38, No. 5, 535-541 (2006). 